\title{
TECHNOLOGY OF DEVELOPING FERTILIZING IN THE ROW AND IMPLEMENTING CONSTRUCTION
}

\author{
T.S.Khudayberdiyev-D.T.S., Professor, A.Kh.Khudayarov- C.T.S., Professor, \\ B.P.Baltabayev- C.T.S., Associate Professor, B.A.Razzakov-Researcher \\ Andijan branch of Tashkent State Agrarian University \\ http://doi.org/10.35410/IJAEB.2019.4488
}

\begin{abstract}
On the purpose of increasing cotton harvest, putting phosphorus fertilizer, while making autumn rows, is being used. The fertilizer should be in the special construction in order to put it in a planned layer. This article suggests a new technology which can put the fertilizer in a wide strap shape, and a construction which can implement it.
\end{abstract}

Keywords: Row-Maker, fertilizer, softening and fertilizing technology, quantity coil, valve controller, wheel supporter, strapped fertilizing technique.

\section{INTRODUCTION}

The method of the last years is spreading the quarry on raw cotton, which has been discussed. The germination of binary seeds in Pashtun is accelerating $2 \ldots 4$ ransom [1].

Increasing Cotton Productivity In the case of Pashto Piano for the purposes of the farmer, the phosphorus fertilizer rate FTZ accelerates to 10 days in Lado [2]. The Fertilizer fertilizer was developed by Pashto Piano tape solid technology, which studied the distribution of fertilizer tapes in Indre Pushto. As a result of the study, the distribution of tape fertilizers in the Pashto is provided in [3].

Based on the results of the research, however, ITT is possible in most of the fertilizer packaging scheme in Hill, namely in Figure 1. 


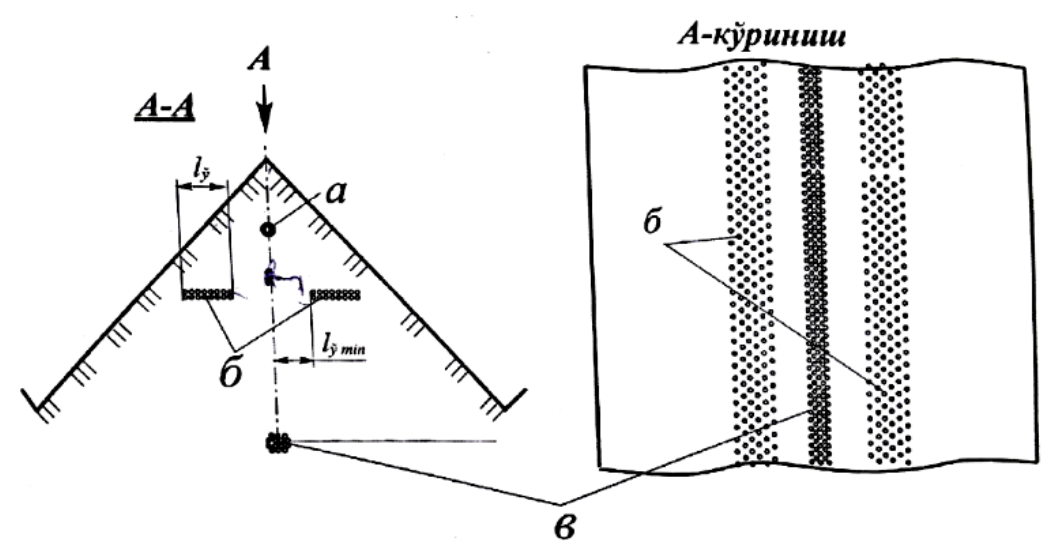

The a-seed is a double-edged trunk, b-high-rigid, c-low

Picture 1 The end of the long back and the movie shooting

We know from the noise of farming, that tornadoculture defeats fertile soil, and the phosphorus fertilizer precipitates in the fall. For this purpose, it is desirable to conduct research in the case of increasing the efficiency of phosphorus fertilizer use, as it is fastened to the back and expanded the film. So, the purpose of the study is to formulate.

The purpose of the survey. Using a sliding, rolled-up strip technology on the back of the mattress and cutting off the annoying backyard grinder.

Problem solving method. The little girl seeks out and checks the area. Back in the checked area. The Pushtinging dimensions were measured at $76 \ldots 80 \mathrm{~cm}$ and based on previous studies, it was assumed to be $28 \mathrm{~cm} 30 \mathrm{~cm}$ high. Figure 2 shows the growth and development of the cusp, the slope of the sliding was determined by the split of the two layers.

Pushtinging is a well-known technology for the application of bulk fertilizers. The Pushtinging technology is shown in Figure 3. The technology is assigned to the back of the top 1, 2 transmitters, the dividers 3 and the radiator- 4 . 


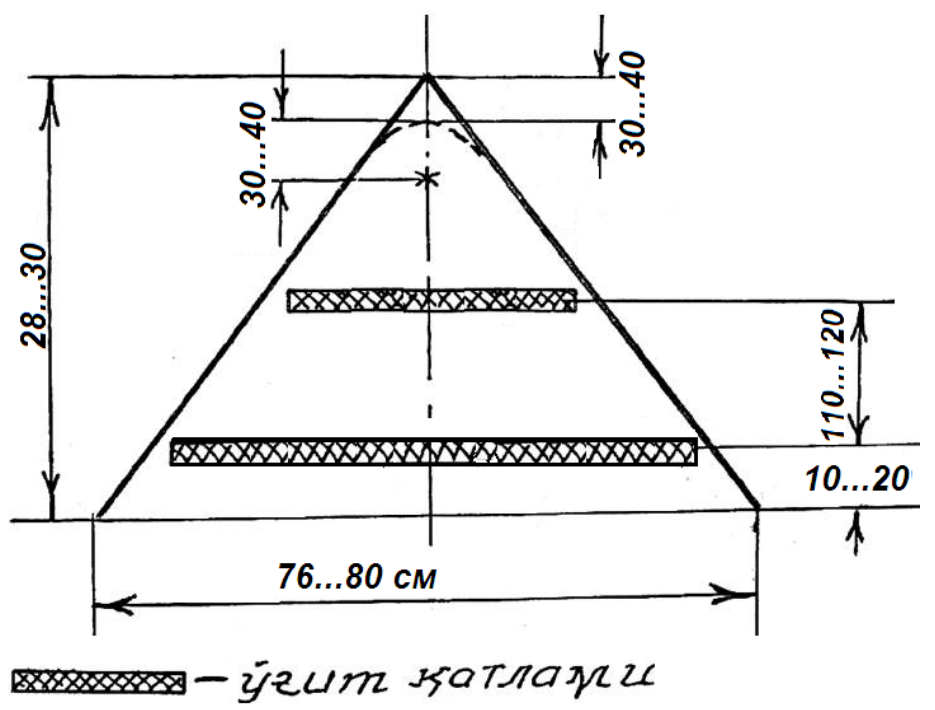

Picture 2 Schematic of layering of texture layers on the backing.

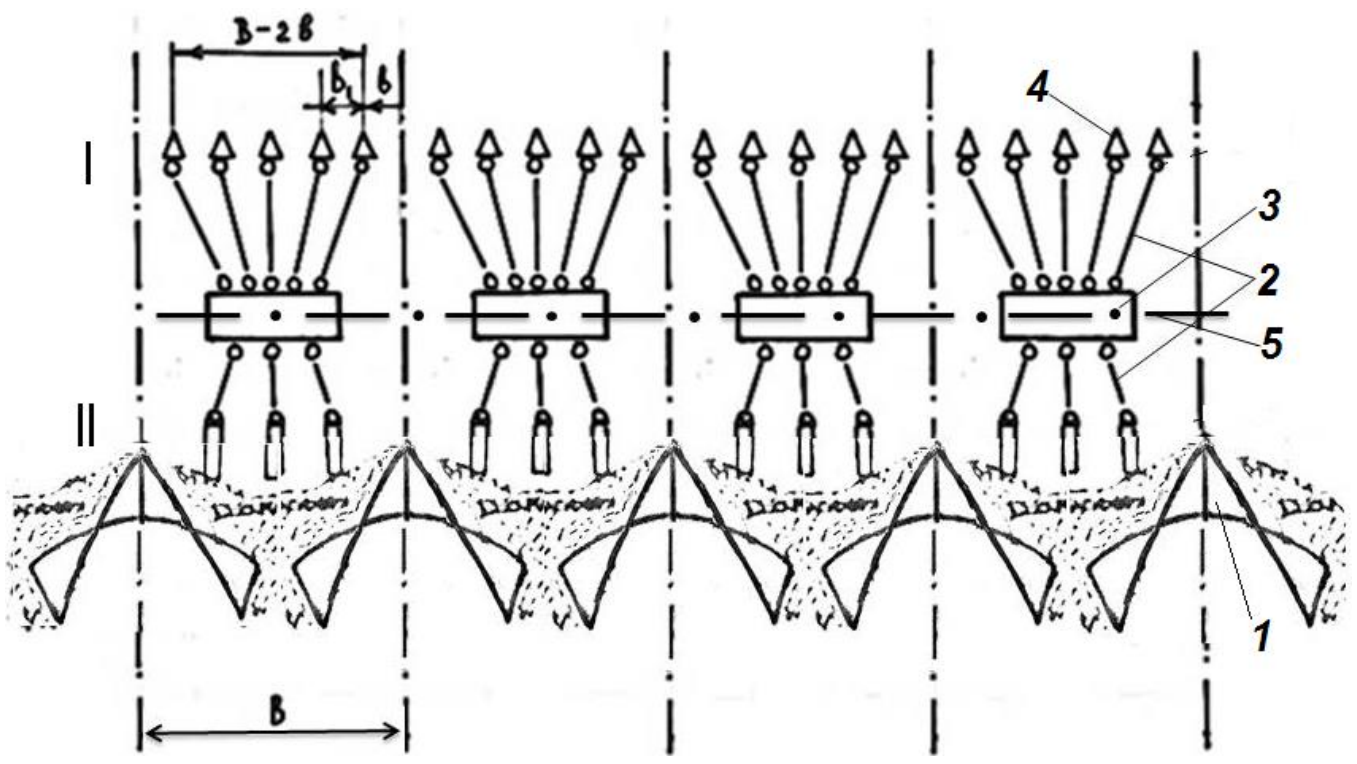

The B-Egg extension; b-chemistry bulletin; b1 -particular distances;

1-back cutter, 2-seeder, 3-scatcher, 4-rifle; 5-scaling valve.

Picture 3 Formulated Pushing technology is a technology used to teach layering

So, the twigs of the twisting blades - ie I and II - from the divisor. The bulk of the first rectangular sturgeon is exposed to each depth of the zipper keg with a teaspoon orchid with a 
depth of $10 \ldots 15 \mathrm{~cm}$. The second slope occurs when the sturgeon is exposed to a tufted yoke or to a depth of $2: 3 \mathrm{~cm}$.

The zirconia on the first line were destroyed at a distance of $18 \ldots 20 \mathrm{~cm}$. The width of the fertilizer device is $2.5 \mathrm{~cm}$ in size. The Yamashgashi people go to the funk dumplings.

The design of the pallet-shaped slab for the left-hand sloping backyard, which has been proposed for the autumn. This design consists of a 1 and cradle frame 2, rim 3, rear suspension 4, ductwork 5, divider 6 , dividing valve 7 , screwdriver 8 , oscillating rod 9 and screwdriver mounting gear 10.

The back burner design is simple and can be eliminated without the labor of writing on flour.

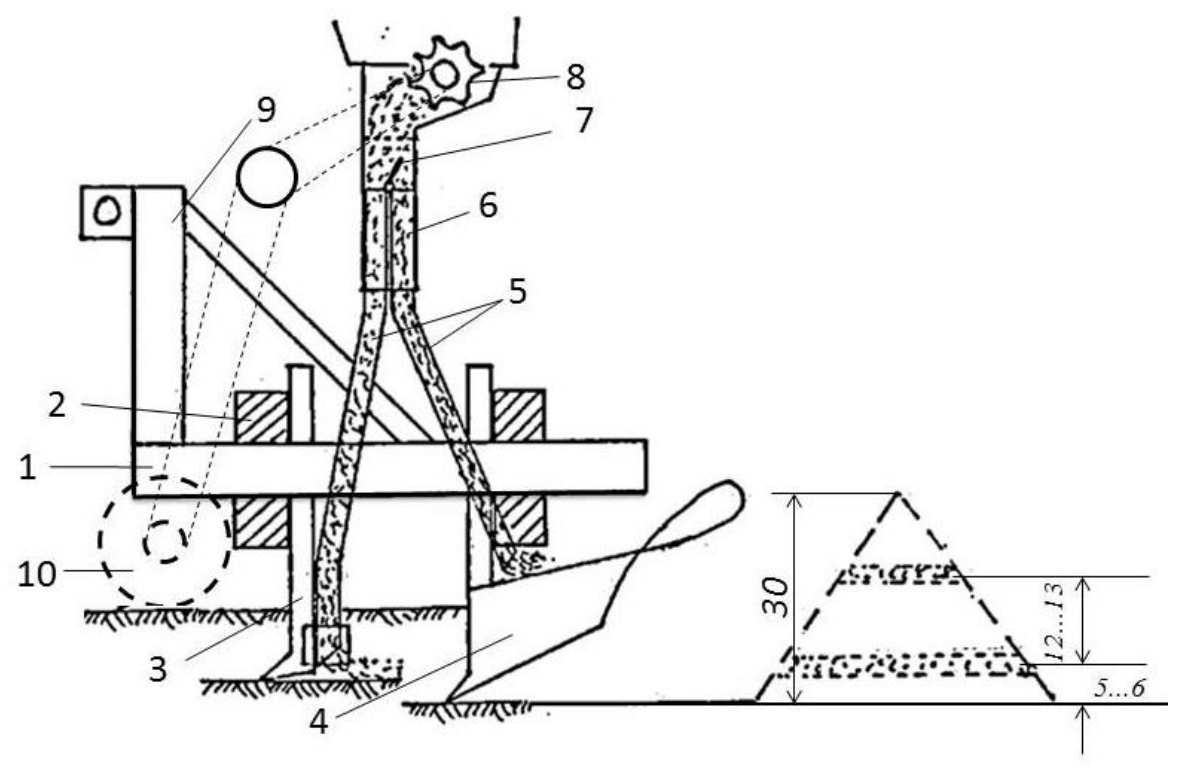

4th Bulletin. Expanded to Pashto layers

fertilizer soldering device

\section{SUMMARY}

1.The exceptionally studied Pashto Push-Fertilizers are designed for placing the fertilizer in the pouch.

2. The development of the cotton jumpsuit system is not only in the upper layer of fertilizer, but also in the GOS, where the pastor layer is embedded in the Beatty tape, probably for the first layer, mineralization ages.

3. Constructions of the plumber Pashto, a fertilizer-fertilizer, were also developed in the form of an expanded fertilizer to the first layer of the Pashta, in spite of this. 


\section{REFERENCE}

Farmer 1.D.Hasanova Pashto Technologies // Agricultural Journal of Uzbekistan.-Business: 2009, 12, 5 .

2.H.Shukurullaev Efficient use of machinery in cotton production and additional possibilities of cotton order.-Business Nihol (2008), 50-53.

Ali 3.N.Komilov Results of research on the development of Pashto mineral fertilizer locale solid machine // Collection of Upper Samaras tractors, agricultural machinery and equipment production and operation. - Business, 2013. - Pages 243-265 